\title{
Las concepciones del docente de primaria en formación sobre el ser humano y el medioambiente desde la educación patrimonial y sus relaciones con la sostenibilidad
}

\author{
The conceptions of the Primary teacher in training about the human being and the \\ environment from heritage education and its relations with sustainability
}

\author{
MORÓN, M.a Carmen ${ }^{1}$ \\ TRABAJO, Mónica ${ }^{2}$ \\ DOMÍNGUEZ, Esperanza ${ }^{3}$
}

\begin{abstract}
Resumen
El artículo explora las concepciones de los futuros docentes de primaria, en relación con el patrimonio cultural y sus relaciones con el medioambiente. Igualmente, trata las problemáticas que surgen de la relación anterior, como las transformaciones y cambios medioambientales, el proceso de globalización y la pérdida de la identidad cultural, entre otros aspectos. Asimismo, indaga sobre qué tipo de metodologías didácticas conocen y emplean los maestros en la enseñanza y aprendizaje de las cuestiones anteriores. En este sentido, se valora si emplean el aprendizaje basado en proyectos o las salidas de campo bajo el enfoque de la educación patrimonial. Finalmente, se valora si estas estrategias permiten alcanzar objetivos educativos como la valoración y conservación del patrimonio cultural y medioambiental bajo una actitud proactiva al desarrollo sostenible.

Palabras clave: Educación patrimonial, concepciones docentes, aprendizaje basado en proyectos, Desarrollo Sostenible.
\end{abstract}

\begin{abstract}
The paper explores the conceptions of future primary school teachers in relation to cultural heritage and its relationship with the environment. It also deals with the problems arising from the previous relationship, such as environmental transformations and changes, the globalization process and the loss of cultural identity, among other aspects. It also inquiries about the type of didactic methodologies known and used by teachers in the teaching and learning of the above issues. In this sense, it is assessed whether they use project-based learning or field trips under the approach of heritage education. Finally, it is assessed whether these strategies allow achieving educational objectives such as the assessment and preservation of cultural and environmental heritage under a proactive attitude towards Sustainable Development.

Key words: Heritage education, teachers' conceptions, project-based learning, Sustainable development.
\end{abstract}

\footnotetext{
1 Universidad de Huelva. España. mcarmen.moron@ddi.uhu.es

2 Universidad de Huelva. España. monica.trabajo@ddcc.uhu.es

${ }^{3}$ Universidad de Huelva. España. esperanza.dominguez@ddi.uhu.es
} 


\section{Introducción}

El presente estudio se centra en conocer cuáles son las concepciones que poseen los futuros docentes de primaria relativas al patrimonio cultural y al medioambiente. Igualmente, se explora si estos docentes son capaces de percibir y comprender la relación de dichos tópicos con el desarrollo sostenible.

Las relaciones del ser humano con su medioambiente han cambiado a lo largo de la historia y de los territorios. Esas relaciones se han articulado como consecuencia de la confluencia de una serie factores. Por un lado, cada sociedad y su cultura mantienen un sistema de ideas y creencias sobre la naturaleza que contribuye a armar el imaginario de esos vínculos. Por otro lado, el conocimiento científico (avances científicos y tecnológicos) ha permitido la explotación y el manejo de la naturaleza conformando distintos sistemas de explotación y extracción de recursos naturales y fuentes de energía, según los territorios y sus necesidades.

La capacidad de transformación del ser humano sobre su medioambiente se ha acelerado en los últimos siglos dentro del contexto de la globalización. Este proceso ha conducido a la homogenización de los sistemas de explotación, de las pautas de consumo y modos de vida, a la pérdida no solo de biodiversidad sino también de diversidad cultural. Por todo ello, las identidades territoriales y sus expresiones culturales en muchas ocasiones están siendo diluidas por este proceso a nivel mundial.

Estas configuraciones territoriales y sus producciones materiales e inmateriales son conocidas y valoradas por las sociedades, ya que son fruto de una cultura en un momento histórico y en un lugar concreto. Todo esto puede ser entendido como patrimonio cultural, de esta forma se puede decir que es la síntesis de las manifestaciones de un pueblo que permite ser explicado y conocido precisamente a través de éstas. El patrimonio no solo abarca al conjunto de bienes materiales e inmateriales sino que también engloba la identidad y la querencia que una cultura y una sociedad manifiesta sobre su territorio. Martín y Cuenca (2015) y Hernández, Martín y Giménez (2017) lo definen como una representación de la identidad en diversas escalas.

Es por ello que, dependiendo de la escala territorial e identitaria, se puede hablar del Patrimonio Global y del Patrimonio Local. El Patrimonio Global es aquel que es identificado y reconocido no solo por un gran número de personas o grupos sociales, sino que también está reconocido por una figura de protección a nivel Internacional, por ejemplo, aquellos bienes denominados por la UNESCO como Patrimonio de la Humanidad. En esta misma línea, se consideran aquellos elementos patrimoniales cuya designación como tal es más antigua, véase el caso de los Parques Nacionales en Estados Unidos (P.N. Yellowstone, 1878, primer parque del mundo), o el de la red de Parques Nacionales de España (P.N. Picos de Europa, 1918, primer parque en España). Este tipo de patrimonio frecuentemente tiene un carácter mediático y es objeto de explotación económica a través del turismo (Fernández, 2006). Igualmente, se le asigna un valor excepcional desde el punto de vista estético y monumental.

Frente al Patrimonio Global, el Patrimonio Local se referiere a aquellos elementos patrimoniales cuyo reconocimiento a nivel territorial queda acotado a un lugar concreto. Además, es reconocido y valorado por un grupo social particular y, frecuentemente, no está reconocido y recogido por la normativa pertinente. Sin embargo, es justamente este Patrimonio Local, el que permite acceder a la compresión de cómo es un territorio y su sociedad y cómo ha funcionado dicho binomio a lo largo del tiempo. Proporciona las pistas necesarias para saber cómo es en el presente y cómo éste pudiera evolucionar en el futuro.

A pesar de esta distinción entre el Patrimonio Global y Local, la comprensión de cualquier elemento o fenómeno patrimonial debe ser abordada desde ambas escalas, con el objeto de comprender de manera integral y más precisa el hecho patrimonial.

El Patrimonio Cultural como síntesis de la sociedad y el territorio (Palazón, 2016; Morón y Morón, 2019), desvela los problemas socioambientales actuales, entre ellos los relativos a la propia dificultad de su conservación. Esto 
último, está vinculado con un enfoque de lo patrimonial de carácter estático y desconectado de los procesos socioeconómicos, culturales y medioambientales (Estepa, Ferreras, López, y Morón, 2011; Estepa y Morón, 2013). Con lo cual, cuando nos acercamos al Patrimonio Cultural también lo hacemos a las dificultades que tienen las sociedades contemporáneas de aproximarse al Desarrollo Sostenible.

El abordaje del Patrimonio Cultural debe ser llevado a cabo desde la escuela para conformar ciudadanos críticos y con capacidad decisoria frente a los desafíos del mundo actual. La educación patrimonial permite entender estas problemáticas socioambientales y culturales, por ello, el primer nivel para conseguir este objetivo educativo sería la formación inicial de docentes, que entiendan, valoren y eduquen en el Patrimonio.

\subsection{Relación entre el ser humano y su medioambiente. La educación patrimonial como elemento para la cohesión de cultura-naturaleza-sociedad}

Así, como veíamos arriba, las relaciones del ser humano con su medioambiente han cambiado históricamente, es por ello que la educación sobre el medioambiente debe ampliarse al entendimiento de los procesos históricos, sociales y culturales (Quintana-Arias, 2017). Dorion (1993) indicaba la importancia de trabajar la educación ambiental y los procesos de desarrollo humano vinculados a los aspectos que tengan que ver con la comprensión cultural, lo cual incentiva la interacción de las personas con su entorno natural al brindarles conocimiento, valores, actitudes, compromisos y habilidades necesarias para proteger la naturaleza.

En este sentido, la sostenibilidad es un tópico clave dentro de la educación patrimonial actualmente. Esta noción es definida en un informe de la Comisión Mundial del Medio Ambiente y del Desarrollo (CMMAD, 1988) como el desarrollo que satisface las necesidades del presente garantizando un equilibrio social, económico y medioambiental que permita la recuperación continuada de los recursos y el bienestar social. Este concepto ha evolucionado en las últimas décadas, haciendo hincapié en buscar el consenso entre: "el desarrollo económico a la conservación del patrimonio cultural y natural, y a la calidad de vida para la humanidad actual y futura, con una doble exigencia ética, de preservación y cuidado de unos recursos naturales que son finitos y de equidad y justicia social" (García, et al. 2019: 2).

Por otro lado, la educación patrimonial se entiende como un proceso que aborda el patrimonio de forma holística e integradora en todas sus manifestaciones (histórica, artística, etnológica, arqueológica, natural y científicotecnológica) como contenido educativo desde una perspectiva simbólico e identitaria de la sociedad y su territorio (Estepa, 2016). Esta tiene entre sus objetivos el fomento de propuestas didácticas investigativas, interdisciplinares y sociocríticas, que conecten a las personas con su entorno mediante vínculos de identidad, individual y colectiva, como arma para la acción en pro de la creación de una ciudadanía sociocultural y ambientalmente comprometida (Cuenca y Martín, 2014). En este punto, es donde la educación patrimonial conecta con la educación medioambiental, ya que ambas se interesan por el Desarrollo Sostenible y por la formación de una ciudadanía crítica y proactiva (Morón y Morón, 2016).

Esta idea es también defendida a nivel internacional por el Consejo de Europa que define la educación patrimonial como "un enfoque de enseñanza basado en el patrimonio cultural, incorporando métodos educativos activos, enfoques transcurriculares y empleando la más amplia variedad de modos de comunicación y expresión" (Comité de Ministros, 1998, p. 31). Las experiencias de educación patrimonial basadas en un contexto territorial concreto, incluyen la construcción de conocimientos sobre el contexto, el paisaje, el territorio y su evolución evidenciando las consecuencias de la expansión de las comunidades, al tiempo que favorece el análisis de los problemas ambientales, etc. (Morón, 2019 y 2020; Morales, Santana y Sánchez, 2017). Por tanto, las propuestas educativas basadas en la educación patrimonial son claves para la gestión eficaz del patrimonio cultural como elemento de cohesión social y como herramienta esencial vinculada al Desarrollo Sostenible 
(Copeland, 2007; Koutrelakos, 2013) ya que permiten “pensar el espacio, observar, preguntar, buscar información, comunicar ideas- y ser capaz de actuar en él” (Pinto y Molina, 2015:105).

Morón y Morón (2016:59) hablan de una educación "enfocada a la transformación crítica de las actitudes que sostienen las relaciones entre humanidad y naturaleza/ entre cultura y naturaleza". Es por ello, que la educación patrimonial permite desarrollar un planteamiento ético-crítico para poder superar la dicotomía naturaleza-cultura y proceder a potenciar el sentido del lugar, de tal forma que los estudiantes podrán desarrollar valores de "conexión, vinculación, enraizamiento, preocupación, cuidado, afecto, humanitarismo, amor, respeto, reverencia y generosidad en relación con el lugar y sus habitantes vivos y no vivos". (Morón y Morón, 2016). Esta aproximación es fundamental para promover una concienciación desde el ámbito educativo basada en el respecto al planeta sobre la base de la sostenibilidad (López-Facal, 2007; Ciscar, 2007; Trabajo y Cuenca, 2017; Gorend y Yemini, 2017).

Desde la Agenda 2030 de Naciones Unidas para el Desarrollo Sostenible se plantean una serie de objetivos dentro de los cuales se diseñan respuestas sistémicas a una visión global e interrelacionada sobre el Desarrollo Sostenible. Particularmente se proponen acciones para afrontar problemáticas tan importantes como la desigualdad y la pobreza extrema, los patrones de consumo no sostenibles y las relaciones entre el ser humano y el medio frente a la degradación. Igualmente, y de manera explícita, recoge una acción orientada a la alfabetización universal; que los alumnos se formen en la promoción del Desarrollo Sostenible y la justicia (De la Rosa, Giménez, Calle, 2019).

La UNESCO y el Consejo de Europa también ponen de manifiesto esta necesidad de incluir la educación patrimonial en los sistemas educativos (Jagielska-Burduk y Piotr, 2019). Aquí cobra vida la figura del docente como agente educativo, sus pensamientos y acciones, guían y orientan su conducta (Escudero y Martínez Domínguez, 2016). Por ello, los estudios sobre las concepciones docentes son prioritarios en las investigaciones educativas (Da-Silva, Mellado, Ruiz y Porlán, 2007) ya que, de estas concepciones dependerán las buenas prácticas que repercutirán posteriormente en la formación de los niños y niñas.

Por último, las propuestas metodológicas más acordes con los planteamientos anteriores son las relativas a metodologías activas y participativas. Así, las salidas fuera del aula, los itinerarios didácticos y el trabajo de campo entre otras, se configuran como las estrategias didácticas esenciales dentro de las propuestas de educación patrimonial. Dichas estrategias afianzan y dan sentido práctico y útil a los contenidos trabajados en el aula (James y Williams, 2017). La experiencia vivencial sobre el contexto favorece el correcto desarrollo del conocimiento social, cultural y natural, en los estudiantes, sea cual sea su nivel educativo y llevadas a cabo desde cualquier área disciplinar (Catlinga, Greenwood, Martin y Owensd, 2010; Jones et al., 2015; James and Williams, 2017; Trabajo y López-Cruz, 2020; Trabajo, 2020). Sin embargo, son abundantes las investigaciones que indican que, en la enseñanza y aprendizaje del patrimonio cultural, independientemente del nivel educativo, sigue siendo mayoritario el uso de estrategias y recursos didácticos más tradicionales, como la clase magistral o el empleo del libro de texto frente a otras estrategias y recursos más activos y de corte indagador. Al tiempo que persiste una visión del hecho patrimonial desde un punto de vista estético (belleza), monumentalista y estático (Ávila, 2003; Estepa, Ferreras, López, y Morón, 2011; Estepa y Morón, 2013; Estepa; Ferreras, y Morón, 2013; Monteagudo y Oliveros, 2016, entre otros).

Estas estrategias de enseñanza y aprendizaje están en la línea del Aprendizaje Basado en Proyectos. Este consiste en: "un modelo de aprendizaje con el cual los estudiantes trabajan de manera activa, planean, implementan y evalúan proyectos que tienen aplicación en el mundo real más allá del aula de clase" (Martí, et al. 2010: p.3). Otros atributos de esta metodología según Bazarra y Casanova (2016) son:

La interdisciplinariedad permitiendo la transferencia y aplicación de los conocimientos de distintas disciplinas.

El aprendizaje competencial del alumnado (saben y saben qué hacer con lo que saben). El alumnado es capaz de autodirigir su aprendizaje en un escenario real. 
Permite al alumnado desarrollar una solución/propuesta, a través de un prototipo o producto final.

En definitiva, estudiar e interpretar el patrimonio cultural y medioambiental, permite a los estudiantes situarse, localmente en su espacio vital y proporcionarles identidad, la cual les será necesaria para sobrevivir en el proceso de mundialización (Fernández, 2006).

Por ello el presente estudio parte del siguiente interrogante: ¿Qué saben los maestros de último año de formación sobre el estudio del medio social, cultural y natural, y el aprendizaje basado en proyectos como método de enseñanza? El estudio se presenta desde una doble perspectiva: por un lado, se enfoca hacia el análisis de los conocimientos adquiridos sobre sociedad, cultura y su medioambiente de los estudiantes en su vida escolar (primaria, secundaria). Por otro lado, se pretende conocer cómo conciben la enseñanza del medio social y cultural en su formación inicial como docentes. A partir de este problema se plantean los siguientes objetivos:

Conocer en qué grado la formación previa de maestros ha tratado aspectos relacionados con el Patrimonio Cultural, el Medioambiente y el Desarrollo Sostenible.

Explorar cómo es la percepción de los futuros maestros sobre las relaciones que establecen entre medio social, cultural, natural y patrimonial.

Conocer qué creen saber los encuestados sobre metodologías exploratorias como el Aprendizaje Basado en Proyectos y las salidas fuera del aula.

Analizar qué actitudes y valores poseen los docentes en formación sobre sostenibilidad del patrimonio.

Conocer cuáles los recursos y materiales didácticos más frecuentemente empleados, por los encuestados tanto en su etapa previa a la formación inicial de maestro como durante esta.

Comprender cuáles son los fines educativos contemplados por los encuestados en relación con la educación patrimonial y medioambiental.

\section{Metodología}

En el presente estudio se realizó un análisis exploratorio sobre las concepciones de 164 maestros y maestras en 40 curso del grado de educación primaria. El estudio que se presenta se enmarca en un posicionamiento metodológico cualitativo de carácter fenomenológico. Dicho estudio está orientado hacia la comprensión de las situaciones únicas y particulares en este caso relacionadas con las concepciones de docentes en formación. El estudio se basa en la Teoría Fundada o Fundamentada, la cual señala que la creación de categorías surge como consecuencia de la interpelación entre el análisis y la recogida de datos (Strauss y Corbin 1994; Bisquerra, 2016).

Nuestro instrumento para la recogida de la información se basó en el diseño de un cuestionario de Google form, el cual fue validado previamente por un comité de expertos. Tras lo cual se pasó a los docentes. En relación con la selección de la muestra podemos indicar que es de conveniencia ya que son estudiantes de una asignatura activa perteneciente al 4 o curso del grado maestros de primaria denominada Proyectos integrados del Medio Social y Cultural durante el curso académico 20-21.

El cuestionario se divide en dos partes. La primera está destinada a conocer las concepciones del maestro en su paso por el sistema educativo español relativas al patrimonio cultural y al medioambiente. Este primer bloque está conformado por cuatro preguntas: una de respuesta abierta y las cuatro restantes son cerradas (Tabla 2). La segunda parte del cuestionario está enfocada a conocer esas mismas concepciones de los docentes durante su formación universitaria para maestro de educación primaria. Este segundo bloque está compuesto por 12 preguntas con respuestas cerradas, bien tipo Likert, multiopción, o selección de un ítem (Tabla 3). 
Hay que señalar que el diseño de las preguntas del cuestionario como el análisis posterior de las respuestas, está guiado por un sistema de categorías (Tabla 1). Dicho sistema de categorías, como ya se indicó arriba, está orientado por la Teoría Fundada o fundamentada, por los objetivos de la investigación y por otros trabajos previos que tratan problemáticas similares (Morón y Morón, 2020; Trabajo y Cuenca, 2020). Este sistema de categoríasf está formado por un descriptor y unos indicadores, que nos permiten conocer las concepciones de los docentes en relación con los objetivos de la investigación. En el siguiente apartado se explica en detalle la estructura de este instrumento.

Por otro lado, el instrumento permite realizar un análisis de los datos tanto en términos descriptivos como analíticos, ya que los datos ofrecidos por las preguntas pueden ser cuantificados en forma de distribución de frecuencias y de porcentajes. Igualmente, en el caso de la pregunta abierta, los indicadores del sistema de categoría nos orientan la interpretación de los resultados, en la medida que son coincidentes las respuestas de los encuestados con los indicadores.

\subsection{Instrumentos de recogida y análisis de la información}

El cuestionario Google-form, fue elaborado en función de las categorías de análisis establecidas para la evaluación de los datos, guiadas por los objetivos de investigación y por el problema de investigación relativo al Patrimonio Cultural y Medioambiental. (Tabla 1).

Tabla 1

Sistema de Categorías

\begin{tabular}{|c|c|c|}
\hline Categorías & Descriptor & Indicador \\
\hline $\begin{array}{c}\text { Conceptualización de la educación } \\
\text { patrimonial y medioambiental }\end{array}$ & $\begin{array}{l}\text { Valora qué conceptos y contenido } \\
\text { sobre el patrimonio y el } \\
\text { medioambiente tratan los maestros } \\
\text { de Primaria }\end{array}$ & $\begin{array}{c}\text { Medio Natural-social-cultural } \\
\text { Cultura } \\
\text { Medioambiente } \\
\text { Globalización } \\
\text { Transformaciones-conflictos } \\
\text { Patrimonio Cultural } \\
\text { Patrimonio Global } \\
\text { Patrimonio Local } \\
\text { Territorio y tiempo }\end{array}$ \\
\hline Metodologías para la E.P. y la E. M.A & $\begin{array}{l}\text { Valora los aspectos metodológicos, } \\
\text { métodos, estrategias y recursos } \\
\text { didácticos, empleados para trabajar } \\
\text { bajo un enfoque Patrimonial }\end{array}$ & $\begin{array}{c}\text { Aprendizaje Basado en Proyectos } \\
\text { Materiales curriculares: libros de texto } \\
\text { Recursos didácticos } \\
\text { Formación Inicial } \\
\text { Formación Continua } \\
\text { Salidas Fuera del aula }\end{array}$ \\
\hline Finalidades de la E.P. y E.A & $\begin{array}{c}\text { Considera las finalidades, objetivos y } \\
\text { los valores y aptitudes que } \\
\text { promueve este enfoque. }\end{array}$ & $\begin{array}{c}\text { Utilidad } \\
\text { Integración de contenidos } \\
\text { Sentido crítico } \\
\text { Cambio y transformaciones } \\
\text { Desarrollo Sostenible }\end{array}$ \\
\hline
\end{tabular}

Fuente: elaboración propia

El sistema de categorías se articula en tres grandes clases que exploran tres dimensiones en torno a la educación patrimonial y la educación medioambiental y que en definitiva responden a los objetivos de la investigación. Ambas temáticas están estrechamente relacionadas con el concepto de Desarrollo y Territorio (Trabajo y Cuenca, 2017; Morón, y Morón, 2020). Así la primera de las categorías es sobre la Conceptualización de la Educación Patrimonial y Medioambiental, se desarrolla a través de una serie de descriptores relacionados con los 
contenidos y conceptos que el docente de Educación Primaria trata o ha podido tratar, tanto en su formación inicial, como en su paso como discente por las distintas etapas del sistema educativo (Tabla 2 y Tabla 3). En este sentido, dichos descriptores son caracterizados a través de unos tópicos denominados como indicadores, que bien de forma directa (Patrimonio global, local, territorio, globalidad, cultura) o de manera indirecta (elación medio natural-social-cultural, Desarrollo Sostenible) permiten una aproximación a las concepciones y creencias de los maestros en torno a las cuestiones nucleares.

La segunda categoría es sobre Metodologías para la Educación Patrimonial y Medioambiental, su descriptor señala los aspectos metodológicos, métodos, estrategias y recursos didácticos afines y adecuados para trabajar bajo un enfoque patrimonial y medioambiental. Es por ello, que los indicadores hacen referencias a metodologías exploratorias e indagatorias en la línea del aprendizaje basado en proyectos y en el contexto (salidas fuera del aula, por ejemplo).

La tercera categoría se centra en las Finalidades educativas de la Educación Patrimonial y Medioambiental, teniendo entre sus descriptores los objetivos y fines educativos que dicho enfoque proporciona al alumnado de primaria y al maestro en formación en la línea de lo que apuntaba nuestro marco teórico. En este sentido, los indicadores están orientados a explorar la utilidad del enfoque patrimonial, la integración de contenidos, el sentido crítico, las aptitudes proactivas hacia el patrimonio y el desarrollo, el cambio y transformaciones, y el Desarrollo Sostenible. Estas nociones y contenidos pueden ser entendidos como fines y metas educativas ya que, en el proceso de comprensión y construcción por los docentes en formación, conducen a cambios en sus valores y sus aptitudes. El cuestionario que se diseña sigue por tanto las categorías y sus descriptores, explorando las creencias y valores que los docentes en formación poseen, así como su experiencia durante su paso por el sistema educativo.

Tabla 2

Preguntas para los maestros como discentes

\begin{tabular}{|c|c|c|c|}
\hline \multirow[b]{2}{*}{ PREGUNTAS } & \multicolumn{3}{|c|}{ SISTEMA DE CATEGORÍAS } \\
\hline & $\begin{array}{l}\text { CAT. I Conceptualización } \\
\text { de La Educación } \\
\text { Patrimonial y } \\
\text { Medioambiental }\end{array}$ & $\begin{array}{l}\text { CAT. II Metodologías } \\
\text { para la E.P. y la e. A }\end{array}$ & $\begin{array}{l}\text { CAT. III } \\
\text { Finalidades de la } \\
\text { E.P. Y E.A }\end{array}$ \\
\hline $\begin{array}{l}\text { P. } 1 \text { ¿Qué contenidos sobre el medio ambiente y la } \\
\text { cultura has trabajado a lo largo de tu paso por el sistema } \\
\text { educativo (etapas de Educación Infantil, Primaria, } \\
\text { Secundaria, Bachillerato o Formación Profesional). Tipo } \\
\text { Respuesta: abierta. }\end{array}$ & & & \\
\hline $\begin{array}{l}\text { P. } 2 \text { Indica el grado de profundidad de los contenidos que } \\
\text { has aprendido sobre el medioambiente y la cultura a lo } \\
\text { largo de tu paso por el sistema educativo (etapas de } \\
\text { Educación Infantil, Primaria, Secundaria, Bachillerato o } \\
\text { Formación Profesional). Respuestas graduadas en } \\
\text { niveles: (bajo, medio, alto), no me acuerdo. }\end{array}$ & & & \\
\hline $\begin{array}{l}\text { P.3 Si te enseñaron conocimiento del medio social y } \\
\text { cultural utilizando el libro de texto como principal } \\
\text { recurso ¿Consideras que el libro de texto reflejaba la } \\
\text { realidad de tu entorno inmediato? Respuestas: Sí, No, } \\
\text { NS/NC. }\end{array}$ & & & \\
\hline $\begin{array}{l}\text { P.4 En tu papel como alumno ¿Te han enseñado } \\
\text { utilizando el ABP? Respuestas: Sí, No, NS/NC. }\end{array}$ & & & \\
\hline
\end{tabular}

Fuente: elaboración propia. 
Tabla 3

Tabla de categorías y preguntas del cuestionario para el análisis de la información para maestros en formación inicial.

\begin{tabular}{|c|c|c|c|}
\hline \multirow[b]{2}{*}{ PREGUNTAS } & \multicolumn{3}{|c|}{ SISTEMA DE CATEGORÍAS } \\
\hline & $\begin{array}{l}\text { CAT. I } \\
\text { Conceptualización de La } \\
\text { Educación Patrimonial y } \\
\text { Medioambiental }\end{array}$ & $\begin{array}{l}\text { CAT. II } \\
\text { Metodologías } \\
\text { para la E.P. y la } \\
\text { e. A }\end{array}$ & $\begin{array}{l}\text { CAT. III } \\
\text { Finalidades de } \\
\text { La E.P. Y E.A }\end{array}$ \\
\hline $\begin{array}{l}\text { P.1 ¿Crees que existe relación entre los conceptos } \\
\text { Medioambiente-Cultura? Respuestas: Sí entre todos, Sí entre } \\
\text { algunos, No existe relación, NS/NC. }\end{array}$ & & & \\
\hline $\begin{array}{l}\text { P.2 ¿Cuál crees que es tu conocimiento sobre la relación entre: } \\
\text { Ser Humano-Medioambiente (social-cultural-natural)? } \\
\text { Respuestas: Escala Likert (1-5, menor a mayor frecuencia) }\end{array}$ & & & \\
\hline $\begin{array}{l}\text { P.3 ¿Cuál crees que es tu conocimiento sobre la relación entre: } \\
\text { Transformaciones-Conflictos el medio (social, cultural y } \\
\text { natural)? Respuestas: Escala Likert (1-5, menor a mayor } \\
\text { frecuencia) }\end{array}$ & & & \\
\hline $\begin{array}{l}\text { P.5 Según tu opinión, ¿en qué grado crees que se trata el } \\
\text { Patrimonio Global en Primaria? Respuestas: Escala Likert (1-5, } \\
\text { menor a mayor frecuencia) }\end{array}$ & & & \\
\hline $\begin{array}{l}\text { P. } 6 \text { ¿Cuál crees que es tu conocimiento sobre la relación entre } \\
\text { Patrimonio-Desarrollo Sostenible? Respuestas: Escala Likert (1- } \\
\text { 5, menor a mayor frecuencia) }\end{array}$ & & & \\
\hline $\begin{array}{l}\text { P.7¿Consideras que la globalización empobrece las culturas } \\
\text { locales? Respuestas: Sí, No, NS/NC. }\end{array}$ & & & \\
\hline $\begin{array}{l}\text { P.11. Indica el grado de conocimiento que crees poseer sobre el } \\
\text { Aprendizaje Basado en Proyectos (ABP). Respuestas graduadas: } \\
\text { superficial, en profundidad, NS/NC. }\end{array}$ & & & \\
\hline $\begin{array}{l}\text { P.12 Señala la frecuencia con la que consideras que se utilizan } \\
\text { los siguientes recursos en el aula para la enseñanza y } \\
\text { aprendizaje del Patrimonio. Respuestas: Escala Likert (1-5, } \\
\text { menor a mayor frecuencia) }\end{array}$ & & & \\
\hline
\end{tabular}

Fuente: elaboración propia.

\section{Resultados y discusión}

\subsection{Categoría I: Conceptualización de la Educación Patrimonial y Medioambiental}

Los resultados de esta categoría se centran en aspectos conceptuales que también señalan finalidades educativas, ya que esos tópicos hacen referencia a relaciones entre elementos, componentes o factores del binomio ser humano-naturaleza que pueden ser objeto de enseñanza en Primaria. 
Los resultados que ha arrojado el cuestionario en aquellas preguntas (P.1 y P.2) realizadas a los maestros en su paso por el sistema educativo son los siguientes:

P.1 ¿Qué contenidos sobre el medioambiente y la cultura has trabajado a lo largo de tu paso por el sistema educativo? Esta pregunta permitía dar respuestas abiertas, por tanto, el análisis de estas respuestas se ha realizado teniendo en cuenta los indicadores de la Categoría I. Las respuestas proporcionadas por el alumnado muestran que los principales contenidos tienen un carácter conceptual y están vinculados con las temáticas recogidas en los bloques de contenidos del currículo a saber: las relativas al ser humano, el medio, la cultura, y que en algunas ocasiones incluyen aspectos concretos como los históricos, población, costumbres, política y economía.

P.2 Indica el grado de profundidad de los contenidos que has aprendido sobre el medioambiente y la cultura a lo largo de tu paso por el sistema educativo. Esta cuestión complementa a la anterior ya que permite aproximarnos al grado de profundidad que creen haber aprendido los maestros en relación con el medio y la cultura.

Es destacable que solo el $8 \%$ de los encuestados indica tener un conocimiento alto frente otros que señalan tener un nivel bajo (25\%) o directamente no se acuerdan (15\%). Es reseñable que en la pregunta 1 aborda qué tipo de contenidos fueron aprendidos casi todos los futuros docentes recuerdan más o menos qué las temáticas se trataron. Sin embargo, las respuestas de la pregunta 2 permiten matizar las declaraciones a la pregunta 1 y suponer que a pesar de que sí son conocidos esos tópicos (cultura, medio, patrimonio), su comprensión y manejo no van necesariamente de la mano (ver gráfico 1).

\section{Gráfico 1}

Grado de profundidad de los contenidos aprendidos sobre el medioambiente y la cultura
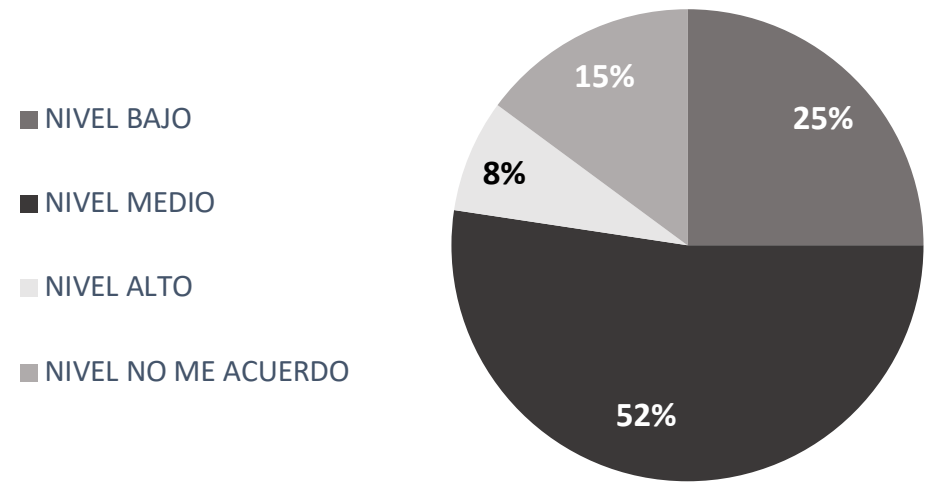

Por otro lado, las preguntas que exploran qué saben los futuros maestros sobre la relación entre medio y la cultura, serían las siguientes:

Los datos (Gráfico 2) que arroja esta cuestión ponen de manifiesto que el 64,6 \% de los futuros docentes señala que existe una clara conexión entre el medio y la cultura, sin embargo, es llamativo que casi un $29 \%$ indica que esa relación existe a veces. La siguiente cuestión explora también el nexo entre ser humano y medio, pero desde el punto de vista del grado de conocimiento que creen tener los docentes en formación sobre dicha relación. Así: P.2 ¿Cuál crees que es tu conocimiento sobre la relación entre ser humano-medio (social-cultural-natural)? 
Gráfico 2

Respuestas de los maestros en formación inicial sobre la relación entre los conceptos de Medio y Cultura en porcentajes

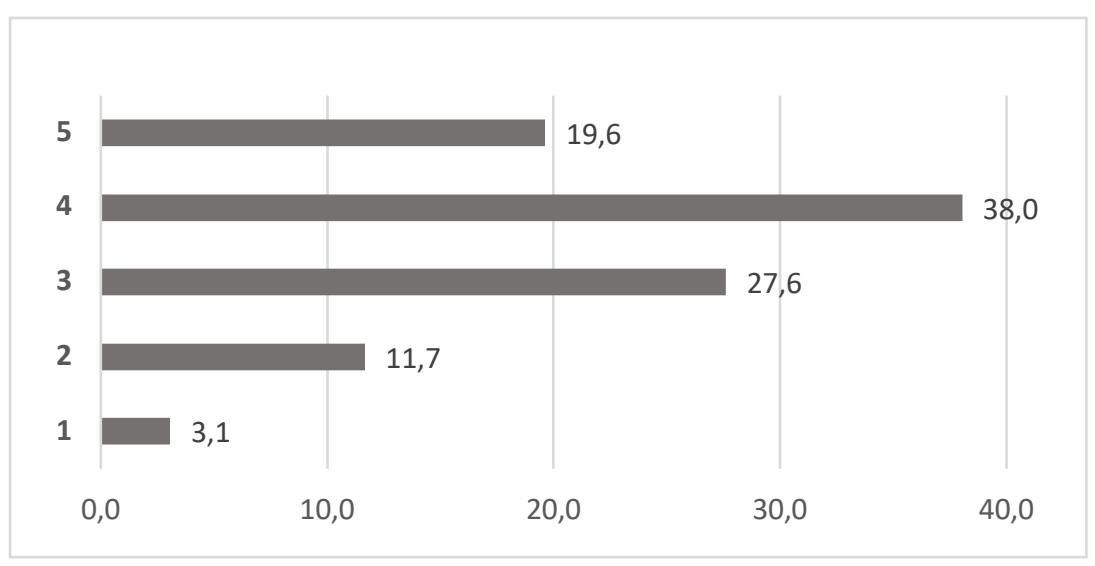

Los maestros en formación indican que creen poseer un elevado grado de conocimiento sobre el ser humano y el medio (Gráfico 3), sumando los valores del grado 4 y 5 prácticamente el $58 \%$ de los encuestados manifiestan tener un grado de conocimiento alto o muy alto, frente al $42 \%$ que conforman los grados bajos e intermedios (1, 2 y 3$)$.

Gráfico 3

Grado de conocimiento de los docentes en relación con el Medio y la cultura

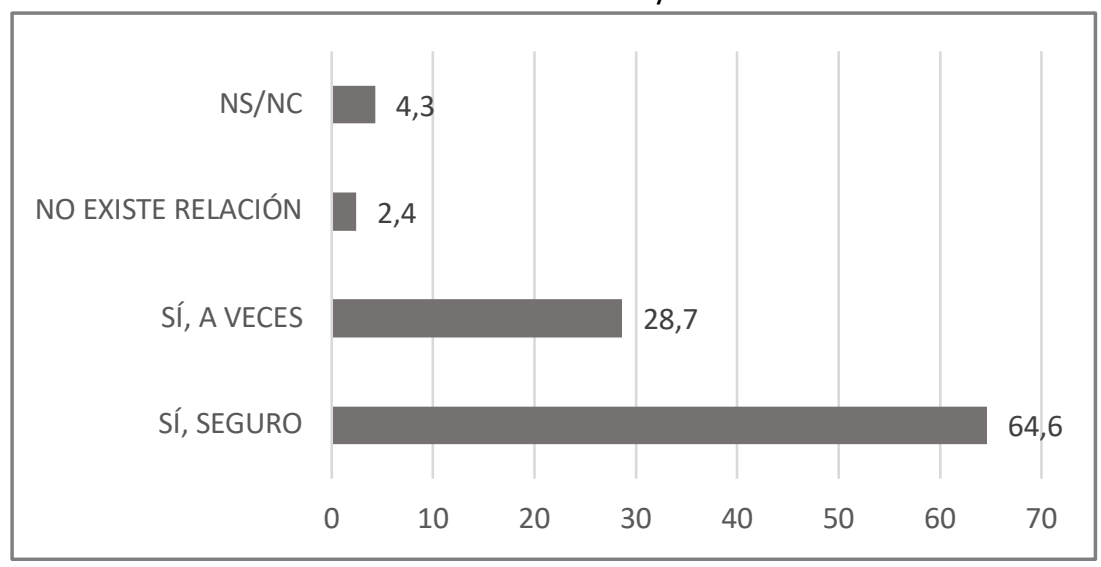

Así en la pregunta 3: ¿Cuál crees que es tu conocimiento sobre la relación entre transformaciones-conflictos el medio (social, cultural y natural) ?, una proporción importante de los encuestados $-43 \%$ - indica tener un grado medio sobre el conocimiento en esa problemática, los niveles superiores de conocimiento, 4 y 5, representan unos porcentajes inferiores a los que se mostraron en la pregunta 3 (relación entre medio y cultura).

Las preguntas 4 y 5 exploran las creencias de los docentes relativas al Patrimonio Local y Global, como dos facetas distintas de un mismo fenómeno. Así en lo relativo al Patrimonio en la escuela se plantea las siguientes cuestiones: P.4 ¿en qué grado crees que se trata el Patrimonio Local en primaria?; P.5 ¿en qué grado crees que se trata el Patrimonio Global en primaria? 


\section{Gráfico 4}

Grado de conocimiento en porcentajes de los docentes en transformaciones-conflictos del medio ambiente.

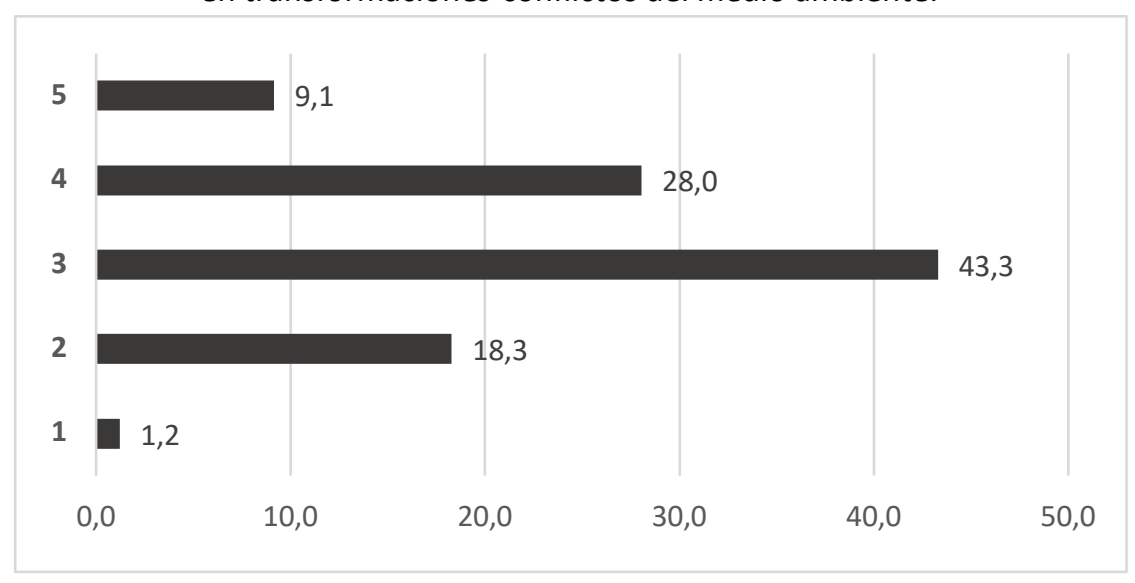

En términos generales las repuestas de los encuestados apuntan a que existe una mayor representatividad de los aspectos relativos al Patrimonio Global en la escuela, como se puede ver, el mayor porcentaje en los grados 4 y 5 , con un $11 \%$ y $30 \%$ respectivamente, frente al $7 \%$ y $24 \%$ en relación con el Patrimonio local en esos mismos grados (Ver gráficos 5 y 6 ).

\section{Gráfico 5}

Grado de conocimiento en porcentajes de los docentes en relación con El Patrimonio Local (P. 4)

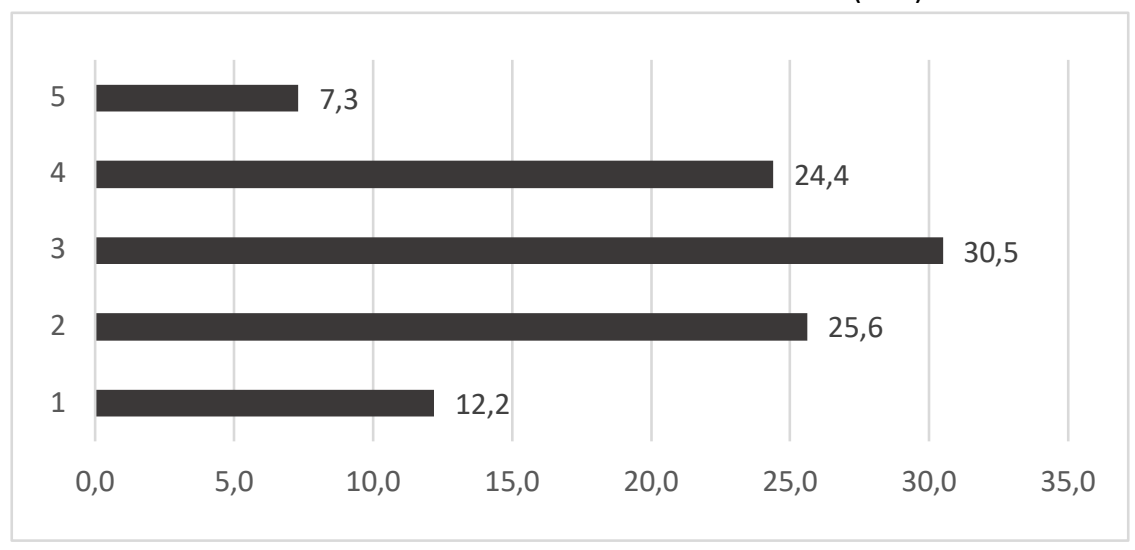

Gráfico 6

Grado de conocimiento en porcentajes de los docentes en relación el Patrimonio Global (P.5)

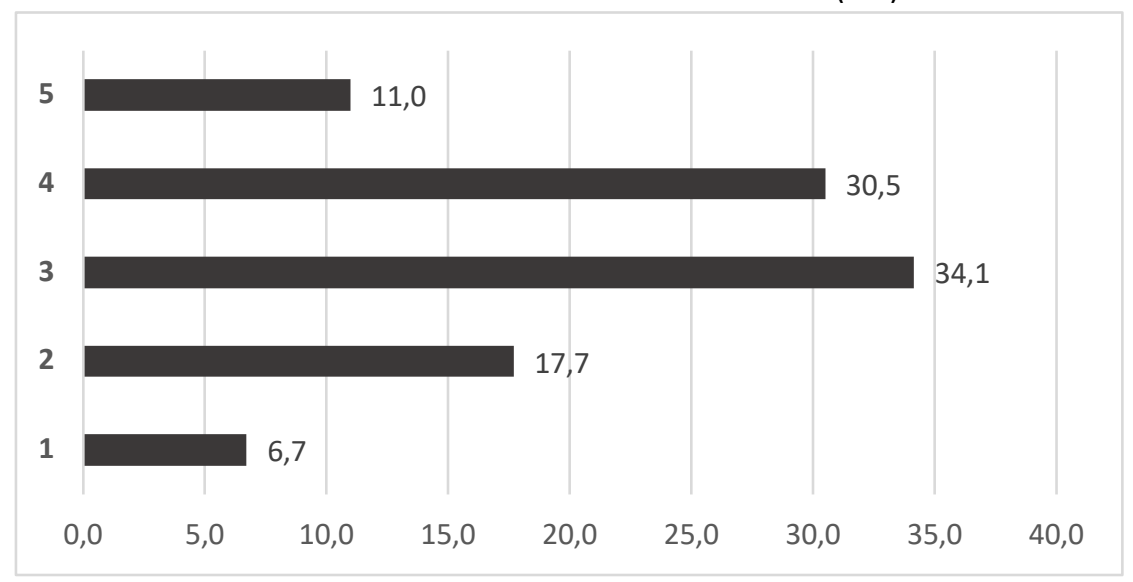


El análisis del patrimonio en la escuela se profundiza a través de la pregunta 6: ¿Cuál crees que es el grado de tratamiento del patrimonio y el Desarrollo Sostenible en la escuela? Los resultados apuntan a que existe una cierta relevancia de esta temática en la escuela, pero en menor medida que el Patrimonio Local, ya que el $34 \%$ de los encuestados cree que se trata frecuentemente en el aula (grado 4) y un $43 \%$ indica que es bastante (grado 3) (Gráfico 7).

\section{Gráfico 7}

Grado de tratamiento en porcentajes que los docentes dan al Desarrollo Sostenible-Patrimonio en la escuela (P. 6)

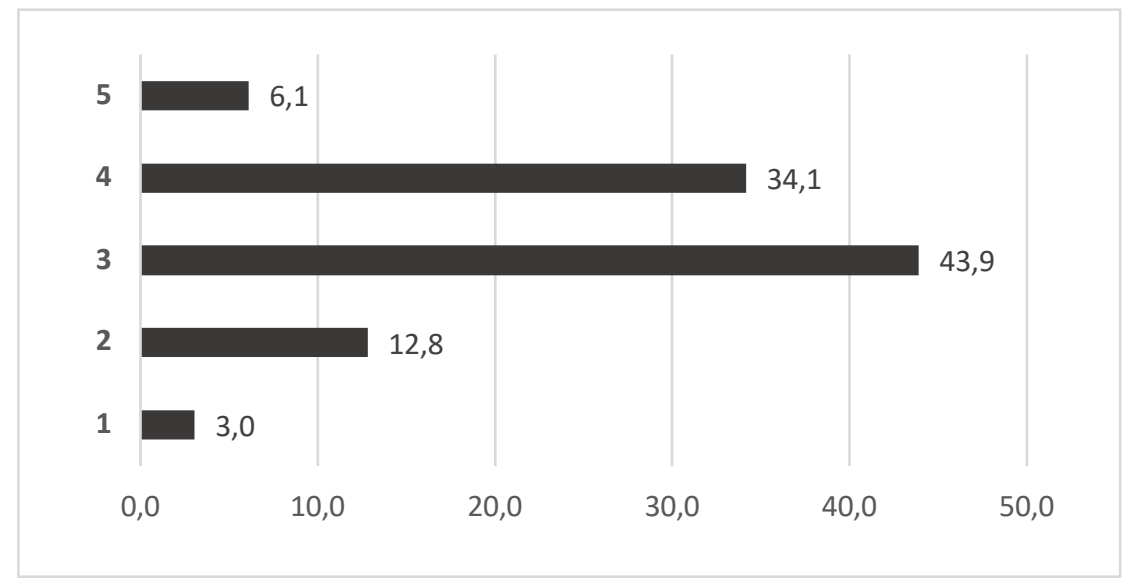

La cuestión patrimonial se aborda de manera indirecta a través de la pregunta 7, expresando la relación entre el fenómeno de la globalización y sus repercusiones sobre las manifestaciones culturales locales. En este sentido se les pregunta a los maestros en formación la siguiente cuestión: P.7¿Consideras que la globalización empobrece las culturas locales?

Los datos aportados por esta pregunta son llamativos, ya que están muy polarizadas las respuestas, prácticamente el $59 \%$ de los encuestados manifiestan que no existen repercusiones negativas para las culturas locales producto de la globalización, frente a esto casi el $42 \%$ dice que sí existe un empobrecimiento de las culturas locales. No hay ninguna respuesta que indique incertidumbre o desconocimiento del alumnado sobre dicha relación (Gráfico 8).

Gráfico 8

Creencias sobre la Globalización y empobrecimiento de culturas locales en porcentajes, (P. 7)

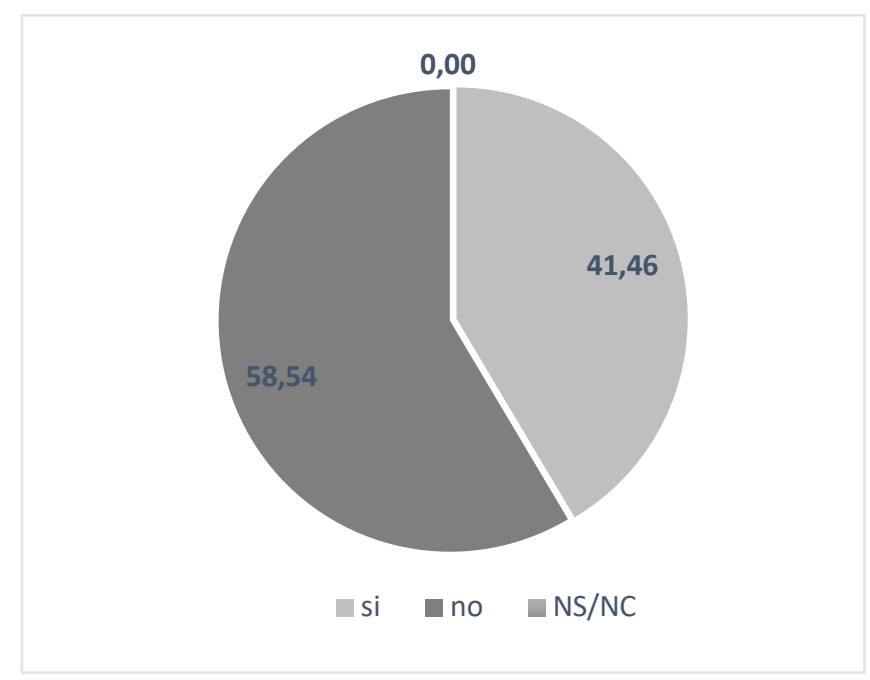


El patrimonio se produce en un contexto territorial y temporal concreto (Patrimonio Territorial), es por ello que se formularon tres preguntas que desglosan la relación entre población, territorio y tiempo (pasado, presente y futuro): P. 8abc ¿Cómo crees qué es de estrecha la relación entre población y territorio en el pasado, en el presente y el futuro? Los resultados de esas tres preguntas se han recogido en un solo gráfico que comparativamente nos permite ver cuáles son las relaciones entre estas variables a lo largo del tiempo (Gráfico 9). Los datos que muestra el gráfico parecen indicar un comportamiento inverso entre población-territorio y pasado y población-territorio y futuro. Así, parece que la relación más reconocida por los maestros en formación es aquella compuesta por población-territorio y pasado, estando representada por los grados 4 y 5 , con un $39 \%$ y $22 \%$ respectivamente, frente al $8,5 \%$ y $1,2 \%$ para los grados 4 y 5 respectivamente referidos al tiempo futuro. El mayor o menor grado de reconocimiento de las relaciones de la población a lo largo del tiempo puede estar vinculado con el concepto de cambio-continuidad. Este aspecto parece indicar un enfoque más o menos estáticodinámico que los docentes tienen sobre el medioambiente y el ser humano. Igualmente, este aspecto se relaciona con la noción de desarrollo, ya que implica tener visión de futuro de cara a la conservación y mantenimiento y disfrute de los bienes, recursos naturales, así como del patrimonio para futuras generaciones.

Gráfico 9

Grado de relación entre la población - territorio a lo largo del tiempo en porcentajes, (P. 8).

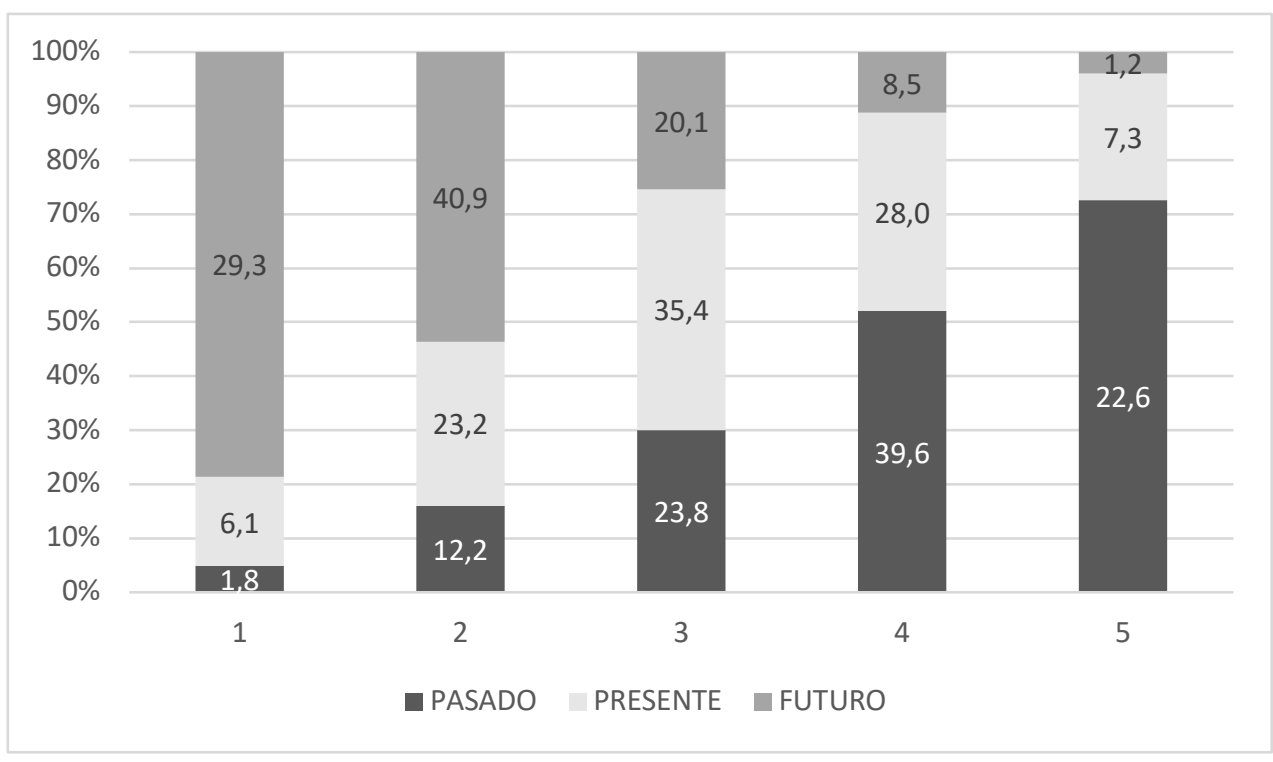

\subsection{Categoría II: Metodología de la enseñanza y aprendizaje de la educación patrimonial y medioambiental}

En esta categoría solo hay dos cuestiones que se le proponen a los maestros en formación, relativas a su paso por el sistema educativo. La primera de ellas es:

La cuestión 3: Si te enseñaron conocimiento del medio social y cultural utilizando el libro de texto como principal recurso ¿Consideras que el libro de texto reflejaba la realidad de tu entorno inmediato? El libro de texto es el principal recurso didáctico empleado en la enseñanza del medio y el entorno, sin embargo, $81 \%$ de estos indican que no reflejan los entornos cercanos frente a un $15 \%$ que piensan que sí lo hacen (Gráfico 10). 
Gráfico 10

El libro de texto y el aprendizaje del

entorno. Resultados en porcentajes

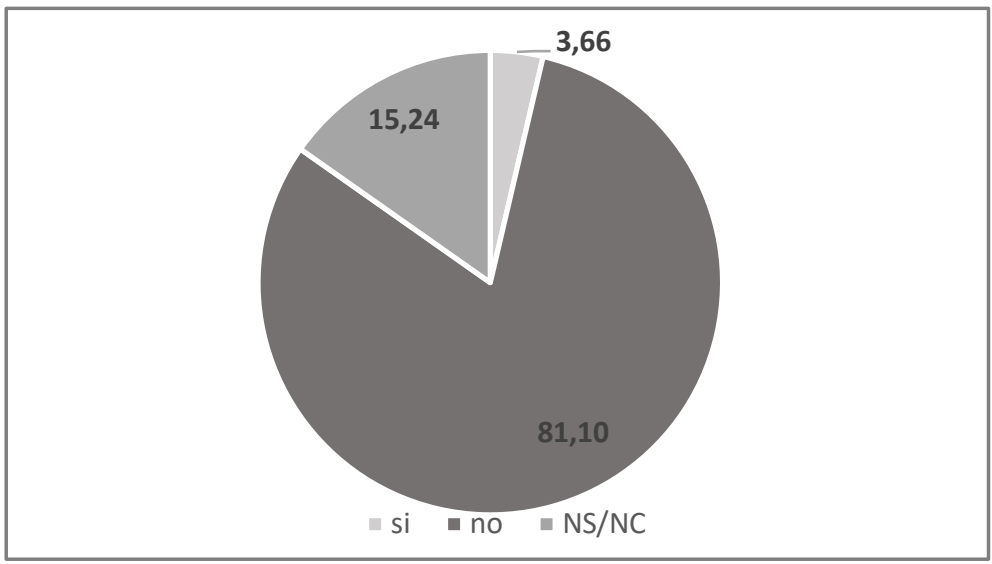

La segunda cuestión explora un aspecto metodológico concreto, el Aprendizaje Basado en Proyectos (ABP), así: P.4 En tu papel como alumno ¿te han enseñado utilizando el ABP? (Gráfico 11)

Los resultados indican que el $81 \%$ de los encuestados señalan que su aprendizaje en la escuela no se basó en $A B P$, aspecto que va en consonancia con las respuestas de la pregunta anterior, las cuales indican un empleo mayoritario del libro de texto.

\section{Gráfico 11}

Experiencia de los maestros sobre ABP como discente por el sistema educativa. Resultados en porcentajes.

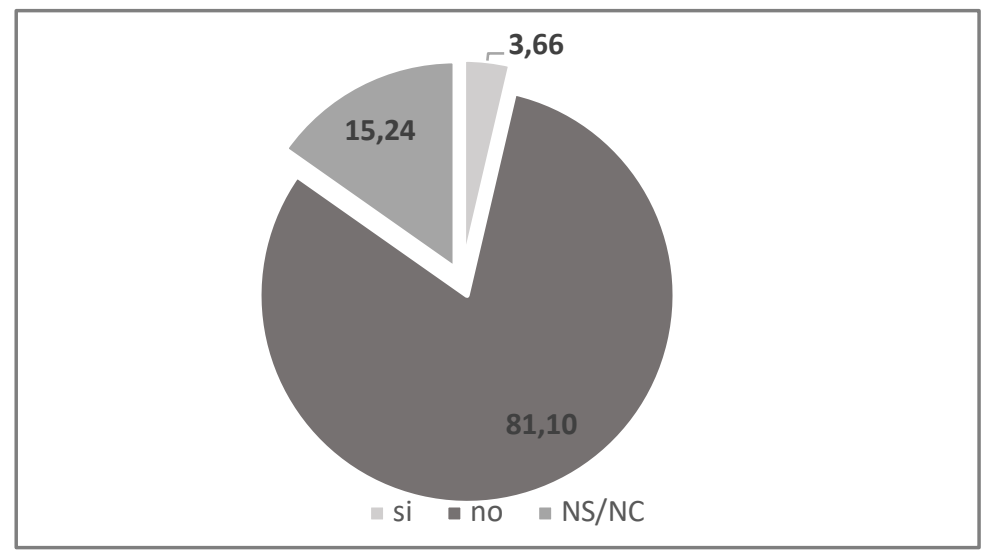

Por otro lado, las cuestiones que se le plantean al docente en formación en esta categoría sobre metodología van referidas a la enseñanza-aprendizaje del patrimonio desde el ABP (P. 9) y si en su formación como docentes han tenido ocasión de planificar unidades con esta estrategia didáctica (P. 10). Igualmente, se indaga sobre la percepción que estos creen tener sobre el ABP (P. 11). Además, el cuestionario también explora el empleo de los maestros en formación de otro conjunto de recursos didácticos (P. 12 y Gráfico 15).

Así en la P.9: ¿Crees que se puede trabajar el patrimonio desde ABP en primaria? Los maestros en formación manifiestan positivamente, casi de manera unánime con un 91\%, que el ABP es una estrategia viable para trabajar el Patrimonio. Igualmente, no existe ninguna respuesta negativa a la pregunta, aunque existe un $9 \%$ de los encuestados que indican no saben o no contestan (Gráfico 12). 


\section{Gráfico 12}

Valoración en porcentajes de los maestros en formación sobre E-A el Patrimonio con ABP

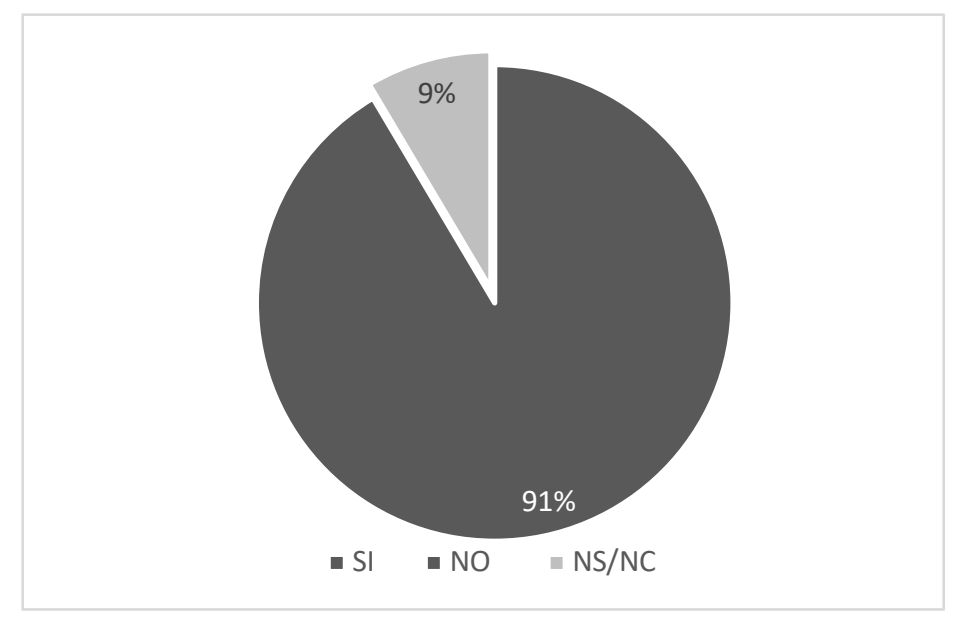

En esta misma línea la pregunta 10: En calidad de futuro docente ¿has planificado unidades de trabajo utilizando el ABP? Esta cuestión explora si la práctica del futuro docente contempla el empleo de esta estrategia metodológica. Así, los resultados mantienen la tendencia de la pregunta anterior, ya que la valoración de los maestros sigue siendo muy positiva (81\%), aunque el porcentaje de ellos que no ha planificado con ABP llega al $14 \%$, y cerca del $5 \%$ reconoce no sabe o no contesta (Gráfico 13 ).

\section{Gráfico 13}

Valoración de los maestros en formación sobre E-A el Patrimonio con ABP

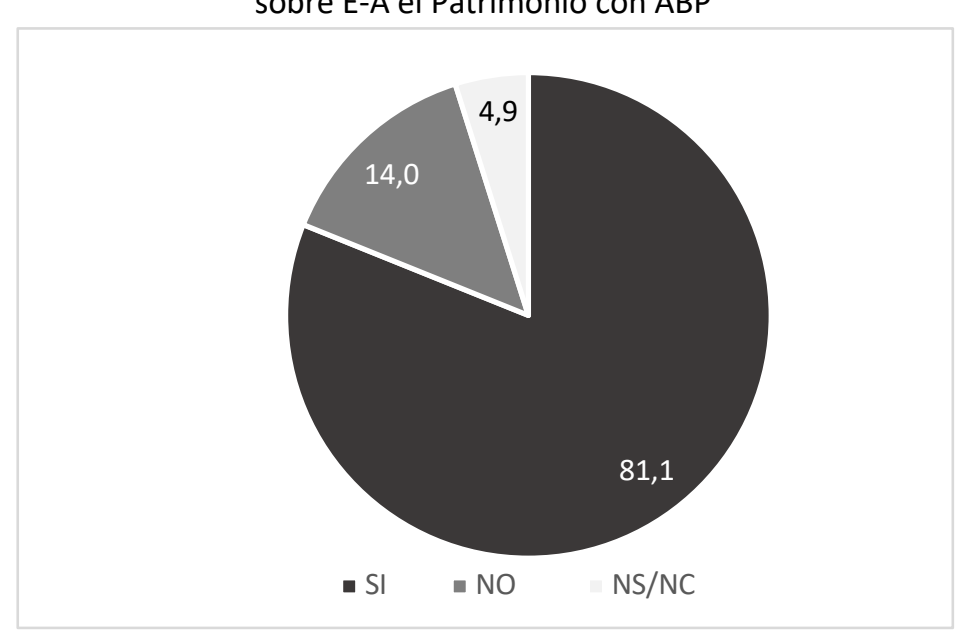

En la pregunta 11 se les solicita a los maestros que indiquen qué grado de conocimiento creen tener sobre esta estrategia. Esta cuestión tiene una doble lectura, conceptual y metodológica, ya que se explora su conocimiento sobre aspectos metodológicos, y también sirve para aproximarnos a cómo y qué podrían enseñar estos maestros. Las respuestas ofrecidas por los maestros señalan que prácticamente la mitad de los encuestados - $53 \%$ - creen tener un grado de conocimiento profundo sobre esta estrategia, frente a un $43 \%$ que piensan que su conocimiento es superficial. Aunque existe porcentualmente una diferencia del $10 \%$ entre unos docentes y otros, estos resultados parecen indicar una predisposición para enseñar y aprender el patrimonio empleando esta metodología (Gráfico 14). 
Gráfico 14

Qué creen saber los maestros sobre ABP

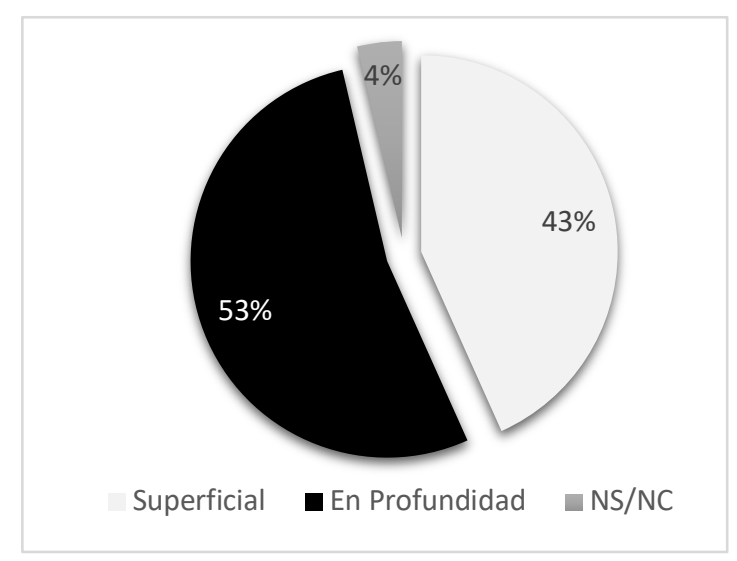

La última pregunta de esta categoría explora el tipo de recursos didácticos y su frecuencia de uso. Así dice: P.12 Señala la frecuencia con la que consideras que se utilizan los siguientes recursos en el aula para la enseñanza y aprendizaje del Patrimonio. Las respuestas se ofrecen en forma de escala Likert, 1 para ninguna y 5 para mucha frecuencia. Las opciones que se le proporcionan a los encuestados van desde los libros de texto hasta el patrimonio como recurso didáctico (Gráfico 15). Los resultados muestran un comportamiento inverso desde los recursos menos tradicionales (Patrimonio Local, salidas fuera del aula y mapas conceptuales) y aquellos que se relacionan con una práctica docente tal vez más tradicional (Atlas, clases magistrales y libro de texto). En este sentido, se puede observar que el libro de texto es el recurso más empleado para tratar el patrimonio en la escuela. Así el 77, 4\% de los encuestados indica que el libro de texto es el recurso más empleado (grado 5), frente al 12,8\% del Patrimonio Local que es el menos empleado (grado 1). El segundo recurso didáctico que tiene mayor frecuencia son las clases magistrales, con un $39,2 \%$ y $37,2 \%$ ocupan respectivamente los grados 4 y 5 . Por el contrario, las salidas fuera del aula tampoco tienen especial representatividad como recurso para la trabajar dicho tópico, ya que su frecuencia de uso es poco o nada frecuente, con un 10,4 \% y 43,3 \% perteneciente a los grados 1 y 2 respectivamente.

\section{Gráfico 15}

Frecuencia en empleo de recursos en el aula para la enseñanza y aprendizaje del Patrimonio

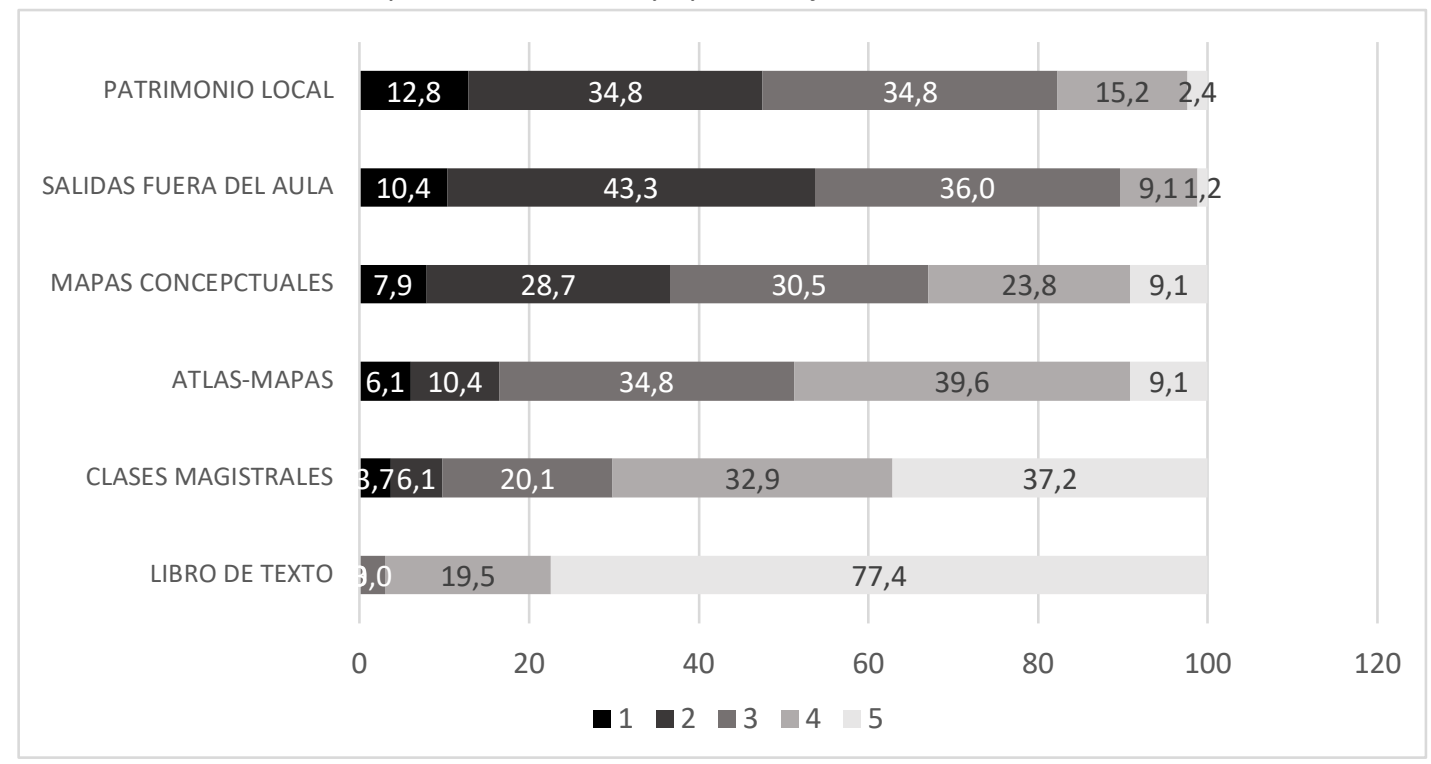




\subsection{Categoría III: Finalidades de la enseñanza y aprendizaje de la educación patrimonial y medioambiental}

En esta categoría se explora las finalidades y las metas educativas que tiene la enseñanza del medio social y cultural. Dentro de la cultura podemos considerar aquellas finalidades educativas que se vinculan con el Patrimonio Cultural, con la identidad y con el territorio. En este sentido, sólo existe una pregunta que formule explícitamente la utilidad y por tanto la finalidad educativa de la enseñanza y aprendizaje del medio en un sentido amplio (P.13): ¿Consideras útil la enseñanza del medio social y cultural en educación primaria?

Las repuestas ofrecidas demuestran que es unánime el reconocimiento de los docentes en lo relativo a la enseñanza del Medio Social y Cultural con un $94,5 \%$ de respuestas afirmativas. A partir de este dato podemos presumir que los docentes tienen cierta predisposición a valorar positivamente otros aspectos que se vinculan con el Medioambiente como el Patrimonio cultural, las transformaciones y los conflictos sociales $y$ medioambientales o el Desarrollo Sostenible.

\section{Gráfico 16}

Utilidad de la enseñanza del Medio

Social-cultural en Educación Primaria

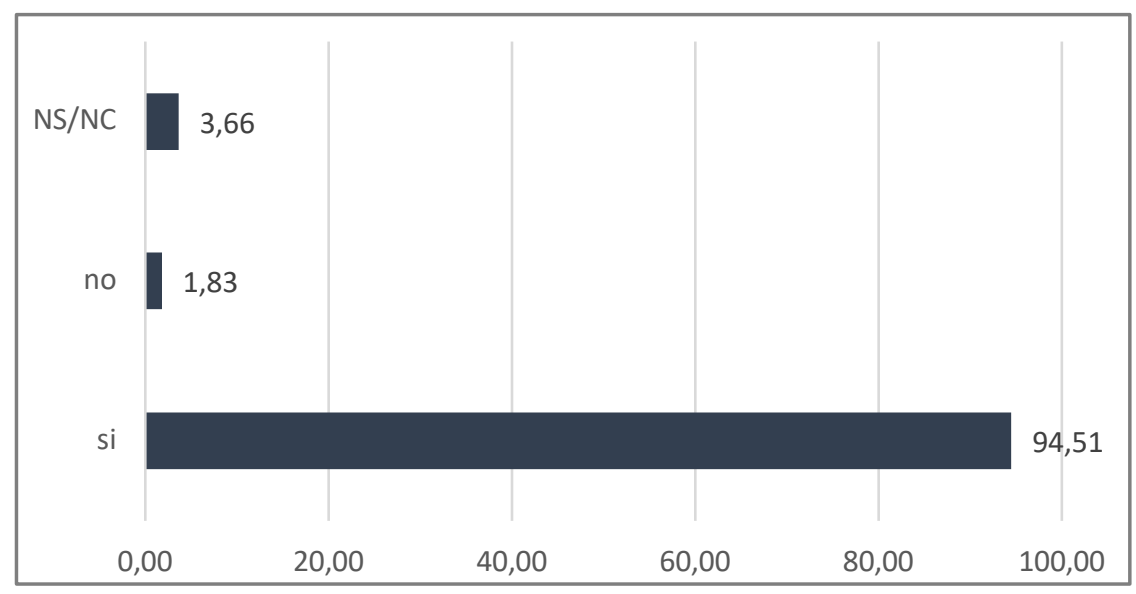

Hay preguntas que, aunque exploran en primera instancia aspectos más conceptuales o metodológicos, también tienen una interpretación en clave axiológica. Esto es debido a que los contenidos tienen tres dimensiones: la conceptual, la metodológica y la actitudinal, esta última vinculada con normas y valores, que pueden ser entendidos como finalidades educativas. La P.1 sondeaba si los maestros reconocían la relación entre el concepto de medio y cultura ( $25 \%$ nivel alto; $52 \%$ nivel medio), en la P2. la relación del ser humano con el medioambiente (64,6\% manifiesta que sí hay relación), es patente que ambas relaciones son reconocidas y relevantes para los maestros. La pregunta 3 se formulaba en relación con el grado de reconocimiento de las transformaciones y los conflictos sobre el medio ambiente, también demostraba un grado de reconocimiento elevado (grado 3: 43,3\% y grado 4: $28 \%$. El Patrimonio Cultural también es reconocido como objeto de estudio para la educación, tanto el Patrimonio Local como el Global. En esta misma línea, la cuestión patrimonio y vinculación con el Desarrollo Sostenible también es contemplada por los maestros, si acaso en menor proporción. Finalmente, el hecho de que los maestros conozcan y reconozcan estos tópicos y sus relaciones entre sí, demuestra que son útiles para ser enseñados y aprendidos en el aula. Así en ese sentido pueden ser entendidos con fines educativos.

\section{Conclusiones}

Los resultados del presente trabajo han indicado que los maestros de primaria en formación reconocen el Patrimonio Cultural como una temática que es relativamente frecuente para enseñar y aprender a través de las relaciones entre el ser humano y el medioambiente como han señalado los datos de la categoría i patrimonio y 
medioambiente. Este reconocimiento que hace el docente en formación también forma parte de su bagaje académico en su paso por el sistema educativo. Sin embargo, aunque el Patrimonio Cultural tiene cierta presencia como tópico y como recurso didáctico en el aula de primaria, cuando se exploran otros aspectos más concretos del patrimonio como la escala de reconocimiento a nivel local y global, los datos indican que en términos generales existe un mayor reconocimiento del fenómeno a nivel local frente al global. Esto está en sintonía con los resultados de otros trabajos, en los cuales se exploran el Patrimonio cultural en libros de texto de Primaria y de Secundaria (Estepa, Ferreras, López, y Morón, 2011; Estepa y Morón, 2013; Estepa; Ferreras, y Morón, 2013). En síntesis, esos estudios apuntan a un mayor reconocimiento del Patrimonio Material frente al Inmaterial, del Patrimonio Monumental y Excepcional, predominando los valores estéticos frente a otros más explicativos relacionados con el territorio, su funcionamiento. Igualmente, el Patrimonio Cultural puede servir de bisagra conceptual para el conocimiento de otras áreas del saber (Monteagudo y Oliveros, 2016; Trabajo y Cuenca, 2020).

Por otro lado, la dimensión temporal del patrimonio (presente, pasado y futuro) y su relación con el territorio también se han explorado. Así, el docente en formación identifica con claridad la relación del patrimonio especialmente con el pasado, entendiendo que es un legado, (Estepa, Ávila, y Ferreras, 2008) y con el presente también es reconocido, pero en menor medida. Sin embargo, el vínculo del Patrimonio con el futuro es el menos patente para los maestros, ello puede deberse a que el maestro no lo enfoca con carácter prospectivo y evolutivo. Este mismo aspecto también ha sido identificado para maestros en formación en Murcia en los trabajos de Ponce, Molina y Ortuño (2015).

En este sentido, la visión de los docentes sobre el patrimonio es la de anclar el fenómeno al pasado (Monteagudo y Oliveros, 2016), y no entenderlo desde un punto de vista dinámico y cambiante. Esto va de la mano con otros trabajos que indican que la perspectiva de los docentes es estática en lo concerniente al medio ambiente y el espacio geográfico siendo similar a la que poseen los niños (Morón, Morón y Martí, 2021).

Esto puede deberse al hecho de que el Patrimonio Cultural y los fenómenos y las problemáticas sociales y medioambientales asociadas a este tópico, se trabajan bajo un enfoque metodológico que no se enseña en el contexto dónde se sitúa y produce el hecho patrimonial (sitios arqueológicos, museos, centros de interpretación de la naturaleza). Tal y como han indicado los resultados de la categoría II de metodología. En este sentido, los libros de textos y las clases magistrales siguen siendo, según la opinión de los docentes, los principales recursos para su enseñanza y aprendizaje, frente a las salidas fuera del aula y el elemento patrimonial como recurso. De igual forma, los libros de texto, promocionan una visión del fenómeno acotada a ejemplificaciones no locales, no cercanas al contexto del alumnado (Morón, 2016; Morón y Morón, 2019; Ponce, Molina y Ortuño, 2015). Además, las actividades que diseñan los manuales escolares no fomentan el aprendizaje ni colaborativo ni indagatorio, que son la base del aprendizaje fuera del aula a través de las salidas (Morón, 2016; Morón, Morón y Abril, 2019; Morón, Morón y Martín 2021). Este aspecto metodológico también puede tener una lectura conceptual y metodológica, en el sentido, que el Patrimonio Cultural enseñado en el aula, emplea frecuentemente recursos didácticos como son el libro de texto, las diapositivas, láminas. Estos recursos didácticos no promocionan una comprensión realista y vivencial del fenómeno patrimonial (Ávila, 2003; Ponce, Molina y Ortuño, 2016). Asimismo, aunque los docentes reconocen el uso de estos recursos más tradicionales, valoran positivamente el empleo del Aprendizaje Basado en Proyectos, y creen tener una actitud óptima para desarrollar actividades con esta metodología didáctica.

La enseñanza y el aprendizaje del nexo formado por el medioambiente, la cultura y el ser humano, son claramente reconocidas por los docentes, tanto en su trayectoria previa por el sistema educativo como en su formación inicial. Esto no es nada nuevo, ya que esa inercia a incorporar estos contenidos en la práctica docente, principalmente contenidos conceptuales, está recogida y fomentada a nivel curricular. Por tanto, los docentes 
tienden a reproducir modelos de enseñanza y aprendizaje en función de cómo a ellos les enseñaron (Carmona, Guzmán, Criado, 2014). Las concepciones sobre las relaciones ser humano, naturaleza y cultura, están más en la línea de una visión sumativa que sistémica e integradora (Morón, Morón y Martín 2021). Y este rasgo también se trasvasa al Patrimonio Cultural, puesto que es un producto de una sociedad y de su tiempo.

Así, una visión más integradora y holística del Patrimonio Cultural en el aula, debe incorporar aquellos aspectos que pasan más desapercibidos para el maestro en formación. Con ello, nos referimos a las transformaciones, conflictos sobre el medio social, cultural y medioambiental, el Desarrollo Sostenible, la globalización, y la pérdida de identidad de las culturas locales. Todos estos tópicos deben ser entendidos en clave de problemas sociales y medioambientales relevantes, por tanto, de interés para los docentes y para su futuro alumnado de primaria. Estos son fines educativos que pueden articularse a través de la educación patrimonial y medioambiental, ya que comparten intereses y finalidades educativas (Morón y Morón, 2016).

Los docentes en formación reconocen mayoritariamente la relación entre el Patrimonio Cultural y el Desarrollo. Junto a esto, otros aspectos colaterales con el Desarrollo Sostenible o más bien, aquellos van el contra de este, como las transformaciones y conflictos del territorio y los efectos negativos de la globalización como el empobrecimiento de las culturas locales Así, son considerados en mayor o en menor medida por los docentes como problemas vinculados con la cuestión patrimonial.

En este sentido, el conocimiento del medio social, cultural y natural engloba la comprensión de las identidades, las formas de vida, del patrimonio cultural y medioambiental y por supuesto del territorio como contexto en el cual se producen los asentamientos humanos (el territorio sin gente es tierra). Por ello, el estudio del medio social, cultural y medioambiental en la formación docentes debe concebirse de forma integrada ya que la sociedad y la cultura van de la mano y éstas sin el medioambiente, no existirían.

Finalmente, existe una visión sesgada del Patrimonio Cultural y su tratamiento en las aulas, cuya solución radica, en parte, en la formación inicial de docentes incorporando la educación patrimonial en los planes de estudio de los grados de educación, tanto de educación infantil como de primaria. Igualmente, debería contemplarse en la formación del profesorado de secundaria. En cualquiera de estos niveles educativos, la educación patrimonial debe tener una vocación integradora, no solo para señalar o identificar aspectos puntuales, anecdóticos o

monumentalistas del hecho patrimonial, sino también para ayudar a superar las barreras disciplinares y buscando un currículo más integrador y competencial.

\section{Agradecimiento}

Agradecemos el apoyo del Proyecto I+D titulado "Patrimonios controversiales para la formación ecosocial de la ciudadanía. Una investigación de educación patrimonial en la enseñanza reglada" (Ref. PID2020-116662GB-I00)

\section{Referencias bibliográficas}

Ávila, R. M. (2003). Dificultades, obstáculos y necesidades formativas de la enseñanza y el aprendizaje del patrimonio histórico-artístico. En E. Ballesteros, C. Fernández J. A. Molina y P. Moreno (Coords.), EI patrimonio y la Didáctica de las Ciencias Sociales (pp. 165-178). Cuenca: asociación Universitaria de Profesores de didáctica de las Ciencias Sociales-Universidad de Castilla la Mancha.

Bazarra , L. y Casanova, O. (2016). La escuela ya no es un lugar. La revolución metodológica está creando futuro. Arcix formación.

Bisquerra, R. (2016). Metodología de la investigación educativa. Madrid. La Muralla. 
Carmona, A. G., Guzmán, M. C. y Criado, A. (2014). ¿Qué hacías para aprobar los exámenes de Ciencias, qué aprendiste y qué cambiarías? Investigación en la Escuela, (84), 31-46.

Catling, S., Greenwood, R., Martin, F. y Owens, P. (2010). Formative experiences of primary geography educators. International Research in Geographical and Environmental Education, 19 (4), 341-350.

Ciscar, J. (2007) La sostenibilidad desde la perspectiva de una ciencia social. Abordar la educación ambiental desde la geografía. En Íber Didáctica de las Ciencias Sociales, Geografía e Historia. 53. 41-51.

Comisión mundial del medio ambiente y del desarrollo (1988). Nuestro Futuro Común, Madrid: Alianza.

Committee of Ministers. (1998) Recommendation No (98) 5 of the Committee of Ministers to Member States Concerning Heritage. Adopted by the Committee of Ministers on 17 March 1998 at the 623rd meeting of the Ministers' Deputies. Available online at: http://rm.coe.int/CoERM Public Comm on SearchService s/Displ ayDCT MContent? documentld =09000 $016804 \mathrm{f} 1 \mathrm{ca} 1$.

Copeland, T. (2007). Heritage Education and citizenship in the Council of Europe. In L. Branchesi (Ed.), Heritage Education for Europe. Outcome and perspective. 65-86. Roma: Armando Editore.

Cuenca, J.M. y Martín, M. (2014). Manual para el desarrollo de proyectos educativos de museos. Gijón: Trea.

Da-Silva, C., Mellado, V. Ruiz, C. y Porlán, R. (2007) Evolution of the conceptions of a secondary education biology teacher: Longitudinal analysis using cognitive maps. Science Teacher Education. 362-491. https://doi.org/10.1002/sce.20183

De la Rosa, D.; Giménez, P. y Calle,. L. (2019). Educación para el desarrollo sostenible: el papel de la universidad en la Agenda 2030. Revista Prisma Social (25), 179-202.

Dorion, C. (1993). Planning and evaluation of environmental education. Council for Environmental Education.

Escudero, J. M. y Martínez-Domínguez, B. (2016). La formación continuada: precisiones, propuestas y advertencias. Cuadernos de pedagogía., (469) 48-50.

Estepa, J. (2016). La educación patrimonial en la escuela y el museo: investigación y experiencias (Vol. 178). Servicio de Publicaciones de la Universidad de Huelva.

Estepa, J. y Morón, M.C. (2013). La educación patrimonial en los materiales didácticos: la visión del profesorado de Ciencias Sociales, Geografía e Historia. En La educación patrimonial en la escuela y el museo: investigación y experiencias (pp. 145-165). Universidad de Huelva.

Estepa, J., Ferreras, M. y Morón, M.C. (2013). Resultados de investigación sobre concepciones del profesorado y gestores del patrimonio y análisis de libros de texto y materiales didácticos de los museos y centros de interpretación del patrimonio. En La Educación patrimonial en la escuela y el museo: investigación y experiencias (pp. 25-39). Universidad de Huelva.

Estepa, J., Ruiz, R. y Listán, M. F. (2008). Primary and secondary teachers' conceptions about heritage and heritage education: A comparative analysis. Teaching and Teacher Education, 24(8), 2095-2107.

Estepa, J.; Ferreras, M., López, I. y Morón, H. (2011). Análisis del patrimonio presente en los libros de texto: obstáculos, dificultades y propuestas. Revista de Educación, (355), 227-228.

Fernández, E. (2006). De tesoro ilustrado a recurso turístico: el cambiante significado del patrimonio cultural. PASOS. Revista de Turismo y Patrimonio Cultural. 4 (1).1-12. 
García, E.; Fernández, J. Rodríguez, F. y Puig, M. (2019). Más allá de la sostenibilidad: por una Educación Ambiental que incremente la resiliencia de la población ante el decrecimiento. Revista de Educación Ambiental y Sostenibilidad 1(1), 1101. doi: 10.25267/Rev_educ_ambient_sostenibilidad.2019.v1.i1.1101

Goredn, H. y Yemini, M. (2017). Global citizenship education redefined- A systematic review of empirical studies on global citizenship education. International Journal of Educational Research. 82. 170-183

Hernández, A. J. M., Martín, D. T. S. y Giménez, L. S. (2017). Identidades territoriales y educación ambiental. Iber: Didáctica de las ciencias sociales, geografía e historia, (89), 12-17.

Jagielska-Burduk, A. y Piotr, S. (2019). Council of Europe Culture Heritage and Education Policy: Preserving Identity and Searching for a Common Core? Revista Electrónica Interuniversitaria de Formación del Profesorado, (22)1-2.

James, J. K. y Williams, T. (2017). School-based experiential outdoor education: A neglected necessity. Journal of Experiential Education, 40(1), 58-71.

Jones, B. D., Chittum, J. R., Akalin, S., B. Schram, A., Fink, J., Schnittka, C. y Brandt, C. (2015). Elements of Design-Based Science Activities That Affect Students' Motivation. School Science and Mathematics, 115(8), 404-415.

López-Facal, R. (2007) Educar para un mundo sustentable. En Íber Didáctica de las Ciencias Sociales, Geografía e Historia. 53. 52-62

Martí, J. A., Heydrich, M., Rojas, M. y Hernández, A. (2010). Aprendizaje basado en proyectos. Revista Universidad EAFIT 46 (158).

Martín, M. J. y Cuenca, J. M. (2015). Educomunicación del patrimonio. Educatio Siglo XXI, 33(1 Marzo), 33-54. https://doi.org/10.6018/j/222491

Monteaguado, J. Oliveros, C. (2016). La didáctica del patrimonio en las aulas. Un análisis de las prácticas docentes. Revista UNES. Universidad, Escuela Y Sociedad, 64. Recuperado a partir de https://revistaseug.ugr.es/index.php/revistaunes/article/view/12150

Morales, A.J., Santana, D. y Sánchez, L. (2017). Íber Didáctica de las Ciencias Sociales, Geografia e Historia. 89. 12-17

Morón, H.; Morón, M.C. (2016). ¿¿ducación Patrimonial o Educación Ambiental?: perspectivas que convergen para la enseñanza de las ciencias. Revista Eureka sobre enseñanza y divulgación de las ciencias, 14(1), 244257.

Morón, H. y Morón, M.C. (2019). La comprensión del patrimonio territorial y medioambiental a través del trabajo de campo. Una propuesta metodológica. En La Reconfiguración del Medio Rural en la Sociedad de la Información Nuevos Desafíos en la Educación Geográfica. 1248- 1253. Santiago de Compostela. Andavira.

Morón, H. y Morón, M.C (2020). ¿ Qué necesidades educativas sobre didáctica de las ciencias demanda el futuro maestro de educación infantil? Revista Espacios, 41 (39), 1-8.

Morón, H., Morón, M.C. y Martin, M.E. (2021). ¿Qué intereses tiene el futuro maestro de educación primaria sobre las salidas fuera del aula?: Una exploración de sus necesidades educativas. En Proceedings of Encuentro Didáctica de las ciencias Experimentales. 981-989. Universidad de Córdoba. 
Morón, M.C. Morón, H. y Abril, D. (2019). La Geografía Escolar a través de los libros de 3ํ de Eso. Una comparativa entre LOE y LOMCE. En La reconfiguración del medio rural en la sociedad de la información: nuevos desafíos en la educación geográfica (pp. 125-138). Santiago de Compostela. Andavira.

Palazón, Mạ. D. (2016). El patrimonio cultural en los estudios de geografía y ordenación del territorio. Didáctica Geográfica (17), 113-136.

Pinto, H., y Molina-Puche, S. (2015). La educación patrimonial en los currículos de ciencias sociales en España y Portugal. Educatio Siglo XXI, 33(1), 103-128. https://doi.org/10.6018/j/222521

Ponce, A. I. P., Molina, S. M., y Ortuño, J. O. (2015). La ausencia de lo patrimonial en la formación de maestros: un estudio en el grado de educación primaria en la Universidad de Murcia. In Una enseñanza de las ciencias sociales para el futuro: Recursos para trabajar la invisibilidad de personas, lugares y temáticas. 567-575. Universidad de Extremadura.

Quintana-Arias, R. F. (2017). La educación ambiental y su importancia en la relación sustentable: HombreNaturaleza-Territorio. Revista Latinoamericana de Ciencias Sociales, Niñez y Juventud, 15(2), 927-949.

Strauss, A. y Corbin, J. (1994). Grounded Theory methodology: An overview. En: N. K. Denzin; Y. S. Lincoln (eds.). The Sage Handbook of Qualitative Research. 443-466. Thousand Oaks, CA: Sage Publications.

Trabajo, M. y Cuenca, J. M. (2017). La educación patrimonial para la adquisición de competencias emocionales y territoriales. Pulso. 40. 159-171

Trabajo, M. y López-Cruz, I. (2019) Implementación del programa Vivir y Sentir el Patrimonio en un centro de enseñanza secundaria obligatoria. Ensayos 34 (1)

Trabajo, M. (2020). La educación patrimonial como vínculo entre escuela y museo: Un estudio de caso para la formación de la ciudadanía en Ciencias Sociales de ESO. Tesis doctoral. Universidad de Huelva

Trabajo, M., y Cuenca, J. Ma. (2020). Student Concepts after a didactic experiment in heritage education. Sustainability, 12(7) 30-46. 